\title{
Inguinal hernia repair under regional anaesthesia versus local anaesthesia: a comparative study
}

\author{
Keshav Y V Prasad, Abhishek Ganguly, Bhargava A N Vyas, Shivaprasad B K Rai, Sri Rama Bhat \\ Department of General Surgery, Kasturba Medical College, Mangalore, India
}

Keywords: Lichtenstein repair; local anesthesia; inguinal hernia; inguinodynia

\begin{abstract}
Introduction

This study aims to compare Lichenstein's repair performed under regional anaesthesia and local anaesthesia.
\end{abstract}

\section{Methods}

This prospective study included two groups of 31 patients each with an uncomplicated inguinal hernia from surgical units of KMC affiliated hospitals. All patients underwent Lichenstein's tension-free repair either under spinal anaesthesia (group 1) or under local anaesthesia (group 2). Results from both groups were compiled and analysed.

\section{Results}

Mean age was 50.45 (SD 16.49) in group 1 and 50.61 (SD 12.04) in group 2. Median time taken for surgery was less under local anaesthesia (1.17 versus 1.5 hours). Postoperative pain was less in the local anaesthesia group at 24, 48 hours after surgery, and after 2 weeks of discharge. Group 1 had higher cases of urinary retention.

\section{Conclusion}

Lichenstein's repair under local anaesthesia was better concerning post-operative pain, complications and hospital stay.

\section{Introduction}

"Hernia is defined as an abnormal protrusion of an organ or tissue through a defect in its surrounding walls" [1].

Inguinal hernia is treated by open or laparoscopic surgery. Lichtenstein repair is an open tension-free repair technique using prosthetic mesh [1]. It can be done under general anaesthesia or regional anaesthesia or local anaesthesia [2,3].

Nowadays, local anaesthesia has gained popularity among surgeons as it results in better satisfaction rates and improves

Correspondence: A N Bhargava Vyas

E-mail: anbhargavvyas@gmail.com

(D) https://orcid.org/0000-0003-4858-6437

Received: 03-07-2021 Accepted: 18-11-2021

DOI: http://doi.org/10.4038/sljs.v39i3.8860 day-case rates [4]. Studies have shown local anaesthesia to be safe, cost-effective and associated with early postoperative recovery [5]. However, general or spinal anaesthesia continues to be popular in developing countries [6]. Hence the purpose of this study is to compare open inguinal hernia repair under local anaesthesia and regional anaesthesia.

\section{Material and methods}

This prospective observational study was done at KMC affiliated hospitals, Kasturba Medical College, Mangalore, India. It included 62 patients with unilateral uncomplicated inguinal hernia (age of and above 18 years). The study was completed between November 2018 and January 2020 after written informed consent and ethical clearance. Patients excluded:

a) Age $<18$ years

b) Obstructed or strangulated hernia

c) Allergy to lignocaine

The sample size was given by:

$\mathrm{N}=2 *(\mathrm{Z} \alpha+\mathrm{Z} \beta) 2 * \sigma 2 / \mathrm{d} 2$

( $\mathrm{Z} \alpha=1.96$ at $95 \%$ confidence interval

$\mathrm{Z} \beta=0.84$ at $80 \%$ power

$\sigma=$ combined standard deviation [3]

$\mathrm{d}=$ mean difference $=0.72[3]$ (of pain scores between regional anaesthesia and local anaesthesia groups))

With a $95 \%$ confidence interval and $80 \%$ power [3], the sample size was calculated to be 31 for each group. A total of 62 patients were ( 31 in each group) enrolled for the study.

The study aimed to compare inguinal hernia repair under regional anaesthesia and local anaesthesia concerning postoperative pain, intraoperative complications, postoperative complications and recurrence.

Non-probability convenience sampling method was used. In group 1, spinal anaesthesia was used and under local anaesthesia in group 2. Lichtenstein tension-free hernioplasty using polypropylene mesh $6 \times 11 \mathrm{~cm}$ was performed in all patients by experienced surgeons. Ceftriaxone $1 \mathrm{~g}$ IV injection was given 30 minutes before surgery.

In group 1, spinal anaesthesia was given using $0.5 \%$ bupivacaine in sitting/lateral position. In the other group, a $1: 1$ combination of $1 \%$ lignocaine and $0.5 \%$ bupivacaine with 
1:200,000 adrenaline solution [3] (15 $\mathrm{ml}$ each) was mixed with $60 \mathrm{ml}$ of distilled water. $20 \mathrm{ml}$ was injected at a point $2 \mathrm{~cm}$ medial to the ipsilateral anterior superior iliac spine deep to external oblique to block ilioinguinal and iliohypogastric nerves. $20 \mathrm{ml}$ then was injected at the same point in the subcutaneous plane using a spinal needle in a fan-shaped manner to block the anterior cutaneous branches of the abdominal wall right up to midline. $15 \mathrm{ml}$ was injected in the subcutaneous plane along the line of the planned incision. After opening the external oblique aponeurosis, $20 \mathrm{ml}$ was injected deep into the external oblique above and below the incision. $15 \mathrm{ml}$ was injected into the cord just medial to the public tubercle to block the genitofemoral nerve. Mesh was anchored using 2-0 polypropylene stitches to an inguinal ligament in a continuous fashion.

Both groups were compared concerning intraoperative complications, duration of surgery, post-operative pain at 24 hours and 48 hours using a visual analogue scale (VAS). Wound hematoma, infection, testicular pain, urinary retention, headache, respiratory complications were assessed postoperatively. After discharge, patients were followed up after 2 weeks, 1 month, 2 months, 3 months and 6 months for wound complications / persistent pain. Recurrence was assessed 6 months after surgery. Student's t-test and chisquare test (SPSS version 17.0 package) were used.

\section{Results}

The mean age for group 1 was 50.45 (SD 16.49) years and for group 2 mean age was 50.61 (SD 12.04) years. The incidence of left-sided hernia was $58.1 \%(n=18)$ in both groups.

No intraoperative complications were noted in either group. Operating time was from the start of administration of anaesthesia till dressing.[3] The median time in group 2 was 1.17 hours versus 1.5 hours in group $1(\mathrm{p}=0.007)$.

The pain was evaluated by using the VAS score (expressed out of 100) (Table 1). The mean VAS score at 24 hours and 48 hours for group 1 was 57.96 and 41.79 for group 2 was 50.61 and 32.26 respectively. The difference in scores at both checkpoints was found to be statistically significant.

Urinary retention and headache were seen among patients of group 1. Wound related complications were found to be similar in both groups (Table 2).

\section{Discussion}

The present study included 62 patients ( 31 in each group) who underwent Lichenstein's open mesh repair - 61 of them were males and 1 female in group 2 with mean age comparable between the two groups. Patients in both groups had no significant intraoperative pain. Although some studies have shown that local anaesthesia was better only in the first few hours after surgery [5,7-8], pain relief was found to be significantly better under local anaesthesia at 24 hours, 48 hours after surgery in our study. 4 patients (out of 31) had persistent pain at 2 weeks after surgery in group 1 while none had in group 2 and this was statistically significant $(\mathrm{p}=0.039)$ (Table 3). Nordin P et al [9] in their trial concluded that local anaesthesia was better than general and spinal anaesthesia in the early postoperative period. Postoperative pain at 12, 24 and 48 hours after surgery was found to be significantly lower in the local anaesthesia group in the study by Goyal P et al [3].

Varied results in the literature have been noted regarding the duration of surgery. Studies by Goyal P et al [3], Ranani MS et al [5], Prakash D et al [8], Bhedi A et al [10] showed no difference in operative time between local and spinal anaesthesia whereas Goel A et al [6] reported longer operative time under local anaesthesia. Similar to studies by Yound DV [2], Song D et al [11], van Veen RN et al [12], Jain A et al [13], operative time was found to be shorter in our study in the local anaesthesia group. This was probably due to the time taken to administer spinal anaesthesia.

Table 1. Postoperative VAS scores

\begin{tabular}{|c|l|l|l|c|}
\hline $\begin{array}{l}\text { Post-operative } \\
\text { pain scores }\end{array}$ & Group & N & Mean & $\begin{array}{c}\text { Standard } \\
\text { Deviation }\end{array}$ \\
\hline \multirow{2}{*}{24 hours } & 1 & 31 & 57.96 & 4.49 \\
\cline { 2 - 5 } & 2 & 31 & 50.61 & 2.74 \\
\hline \multirow{2}{*}{48 hours } & 1 & 31 & 41.79 & 8.97 \\
\cline { 2 - 5 } & 2 & 31 & 32.26 & 3.80 \\
\hline
\end{tabular}

Table 2. Post operative complications and hospital stay

\begin{tabular}{|c|c|c|c|c|c|}
\hline \multirow{3}{*}{\multicolumn{2}{|c|}{$\begin{array}{l}\text { Post-operative } \\
\text { complications }\end{array}$}} & \multicolumn{4}{|c|}{ Group } \\
\hline & & \multicolumn{2}{|c|}{1} & \multicolumn{2}{|c|}{2} \\
\hline & & \multirow{2}{*}{$\frac{\text { Count }}{29}$} & \multirow{2}{*}{$\begin{array}{l}\begin{array}{c}\text { Column } \\
\mathrm{N} \%\end{array} \\
93.5 \%\end{array}$} & \multirow{2}{*}{\begin{tabular}{c|} 
Count \\
30
\end{tabular}} & \multirow{2}{*}{$\begin{array}{c}\begin{array}{c}\text { Column } \\
\mathrm{N} \%\end{array} \\
96.8 \%\end{array}$} \\
\hline Hematoma & No & & & & \\
\hline & Yes & 2 & $6.5 \%$ & 1 & $3.2 \%$ \\
\hline & Total & 31 & $100.0 \%$ & 31 & $100.0 \%$ \\
\hline \multirow[t]{2}{*}{ Infection } & Yes & 0 & $0 \%$ & 0 & $0 \%$ \\
\hline & Total & 31 & $100.0 \%$ & 31 & $100.0 \%$ \\
\hline \multirow{2}{*}{$\begin{array}{l}\text { Testicular } \\
\text { pain }\end{array}$} & Yes & 0 & $0 \%$ & 0 & $0 \%$ \\
\hline & Total & 31 & $100.0 \%$ & 31 & $100.0 \%$ \\
\hline \multirow{3}{*}{$\begin{array}{l}\text { Urinary } \\
\text { retention }\end{array}$} & No & 26 & $83.9 \%$ & 31 & $100.0 \%$ \\
\hline & Yes & 5 & $16.1 \%$ & 0 & $.0 \%$ \\
\hline & Total & 31 & $100.0 \%$ & 31 & $100.0 \%$ \\
\hline \multirow[t]{3}{*}{ Headache } & No & 28 & $90.3 \%$ & 31 & $100.0 \%$ \\
\hline & Yes & 3 & $9.7 \%$ & 0 & $.0 \%$ \\
\hline & Total & 31 & $100.0 \%$ & 31 & $100.0 \%$ \\
\hline
\end{tabular}


Table 3.Follow up

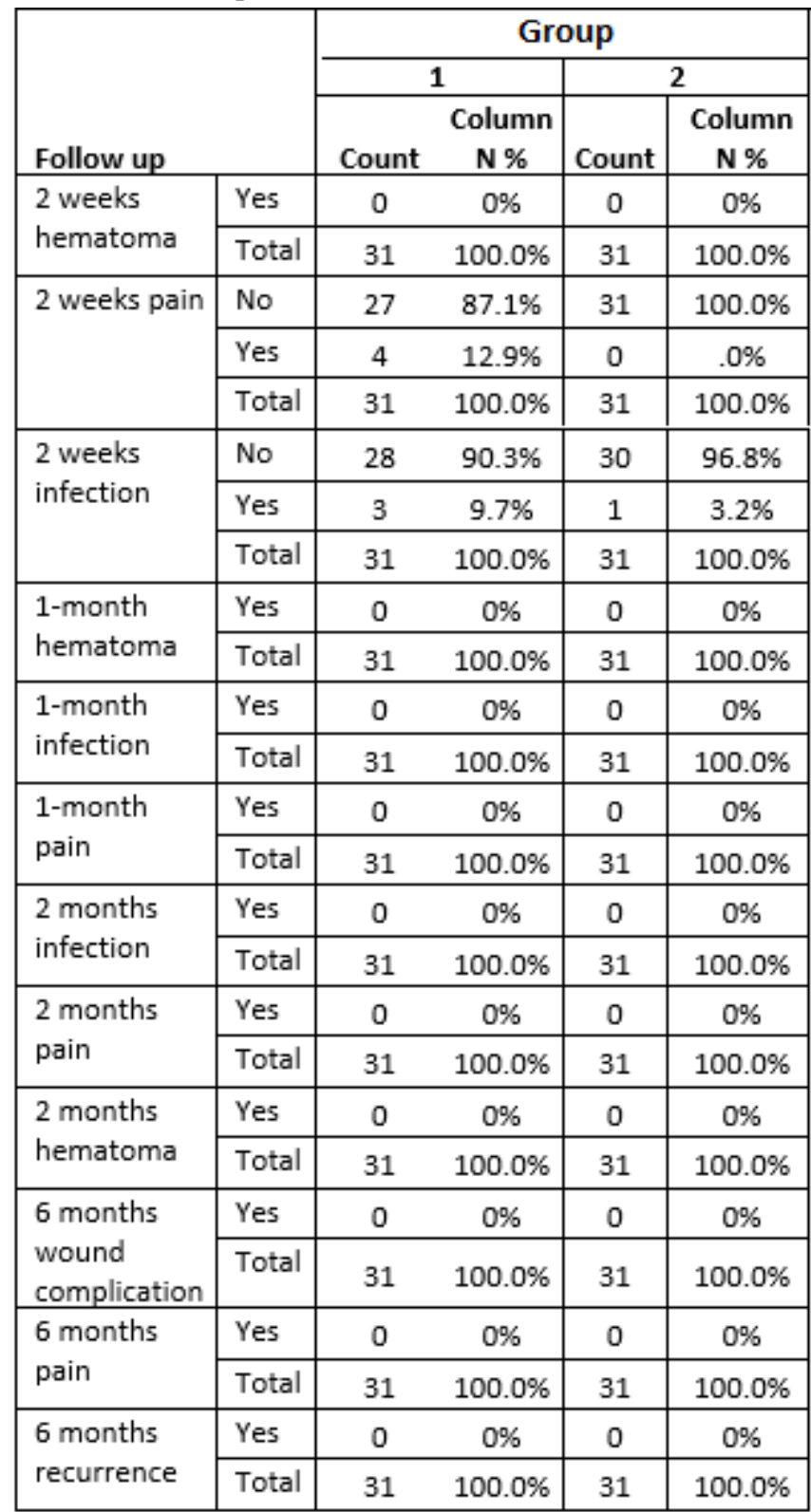

As reported by Young V [2], van Veen RN et al [12], Jain A et al [13] and Subramaniam $P$ et al [14] urinary retention postoperatively was a significant complication in the spinal anaesthesia group in our $\operatorname{study}(\mathrm{p}=0.02)$. No significant difference between wound-related complications was noted. In our study, patients from distant areas were admitted who were allowed to stay until they opted for discharge. The criteria of pain at the time of discharge and hospital stay was not considered for final analysis as the duration was not based solely on the clinical condition but also affected by social and demographic factors for the patients.

\section{Conclusion}

In our study, Lichenstein's repair under local anaesthesia was found to have lower operative time and postoperative urinary retention and pain scores, which were statistically significant. No statistical difference was noted in the wound-related complications in both groups. Under local anaesthesia, the patient may be asked to cough intraoperatively to locate thin sacs as the abdominal musculature is not paralysed [13]. With some experience, local anaesthesia can be administered by the surgeon himself and this can be a cost-effective alternative in peripheral health centres. With no spinal anaesthesia related complications, Lichenstein's repair under local anaesthesia is appropriate. As our study included 62 patients, studies with a higher sample size may be needed to support our findings.

All authors disclose no conflict of interest. The study was conducted in accordance with the ethical standards of the relevant institutional or national ethics committee and the Helsinki Declaration of 1975, as revised in 2000 .

\section{References}

1. Townsend, Beauchamp, Evers, et al. Hernias (2017) In: Sabiston textbook of surgery: The Biological Basis of Modern Surgical Practice, Elselvier, Philadelphia, 20th Ed p. 1092-93

2.Young DV (1987) Comparison of local, spinal and general anaesthesia for inguinal hernia repair. Am J Surg 153:560-3. https://doi.org/10.1016/0002-9610(87)90154-1

3.Goyal P, Sharma SK, Jaswal KS, et al (2014) Comparison of inguinal hernia repair under local anesthesia versus spinal anesthesia. IOSR-JDMS 13:54-59

https://doi.org/10.9790/0853-13165459

4. Sanjay P, Woodward A (2007) Inguinal Hernia Repair: Local or General Anaesthesia? Ann R Coll Surg Engl. 89: 497-503. https://doi.org/10.1308/003588407X202056

5. Ranani MS, Moghaddam NG, Firouzian A, et al (2015) A Comparison between Local and Spinal Anesthesia in Inguinal hernia Repair. Int J Clin Anesthesiol. 3:1041.

6. Goel A, Bansal A, Singh A (2017) Comparison of local versus spinal anesthesia in long standing open inguinal hernia repair. Int Surg J. 4:3701-3704

三https://doi.org/10.18203/2349-2902.isj20174889

7. O'Dwyer PJ, Serpell MG, Millar K, et al (2002) Local or general anaesthesia for open tension-free hernioplasty: A randomized trial. Ann Surg. 237:574-79.

https://doi.org/10.1097/01.SLA.0000059992.76731.64

8. Prakash D, Heskin L, Doherty S, et al (2017) Local anaesthesia versus spinal anaesthesia inguinal hernia repair: A systematic review and meta-analysis. Surgeon. 15:47-57.

https://doi.org/10.1016/j.surge.2016.01.001

9. Nordin P, Zetterstrom H, Gunnarsson U (2003) Local, regional or general anaesthesia in groin hernia repair: Multicentre randomized trial. Lancet. 362:853.

https://doi.org/10.1016/S0140-6736(03)14339-5 
10.Bhedi A, Damor S, Sarkar A (2016) Inguinal Hernia Repair: Comparison of Local Anaesthesia and Spinal Anaesthesia. JMSCR 4:14540-14547

https://doi.org/10.18535/jmscr/v4i12.40

11.Song D, Greilich NB, White PF, et al (2000) Recovery profiles and costs of anaesthesia for outpatient unilateral inguinal herniorrhaphy. Anaesth Analg. 91:876-81.

https://doi.org/10.1097/00000539-200010000-00020

12.van Veen RN, Mahabier C, Dawson I, et al (2008) Spinal or local anaesthesia in Lichtenstein hernia repair: A randomized controlled trial. Ann Surg. 247:428-33.

https://doi.org/10.1097/SLA.0b013e318165b0ff
13.Jain A, Jain R, Choudhrie A. (2019) Local Anaesthesia Versus Spinal Anaesthesia in Inguinal Hernia Surgery-An Evidence Based Approach. IJARS 8: SO01-SO04

14.Subramaniam P, Leslie J, Gourlay C, et al (1998) Inguinal hernia repair: A comparison between local and general anaesthesia. Aust NZJ Surg. 68:799-800.

https://doi.org/10.1111/j.1445-2197.1998.tb04680.x 